Eur J Clin Nutr 45, 569-581], underreporting was defined with a value $<1.14$ for an individual subject in the ratio (energy intake)/(basal metabolic rate computed according to Schofield).

Using this criteria, 55\% $(n=229)$ of the subjects were classified as UR. The proportion of women was increased in the UR group compared to non-UR subjects ( $91 \%$ vs $67 \%, P<0.000,001)$ and analyses were performed separately in each gender. In women as in men, obese UR compared to non-UR were characterized by an increased protein intake (about $20 \%$ vs $15 \%$ of total energy intake, $P<0.000,001)$ and an increased proportion of restraint subjects $(P<0.05)$, whereas age and BMI were comparable between the two groups.

In conclusion, in obese patients seeking advice in a hospital setting, dietary underreporting: 1) concerns predominantly female subjects, 2) may be related to certain macronutrients, and 3) appears to be associated with dietary restriction.

\section{Cooking and dressing fats in Sardinia} and Corsica. AM Carcassi ${ }^{1}$, J Giannettini $^{2}$, I Carta ${ }^{1}$, R Coinu ${ }^{3}$, P Pranzetti ${ }^{3}$, A Luciani ${ }^{2}\left({ }^{l}\right.$ Fisiologia Umana, Universita, Via Porcell, 4, 09124 Cagliari, Italy; ${ }^{2}$ Faculté des sciences, université de Corse, $B P$ 52, 20250 Corte, France; ${ }^{3}$ Fisiologia Generale, Universita, Via Muroni, 25, 07100 Sassari, Italy).

The type of fat used in cooking and dressing is essential to ensure a proper intake of saturated, monounsaturated and polyunsaturated fatty acids. The aim of this work is to compare the eating habits on two islands of the Mediterranean Sea. The research was performed from written answers to a questionnaire which involved 1022 Sardinian and 465 Corsican families. The statistical analysis ( $\chi$ test) shows significant differences $(P<0.001)$ between the two islands:
- for sauce preparation, meat and fish cooking, at least $75 \%$ of the Sardinian families use olive oil whereas two Corsican families out of three use other vegetable oils;

- for salad dressing of raw and cooked vegetables, a large majority of the Sardinian families ( $>90 \%$ ) use olive oil whereas in Corsica, although $65 \%$ of the families consume olive oil, $23 \%$ used other vegetable oils;

- for frying, Sardinian families use other vegetable oils (64\%) more often than olive oil (34\%). In Corsica, other vegetable oils are mostly used $(88 \%)$;

- finally, for pastry, we note an important use of solid fats: in Sardinia, lard (39\%), butter $(36 \%)$ and margarine $(27 \%)$ are prevalent whereas in Corsica it is butter (65\%).

Consequently, these two neighbouring islands of the Mediterranean Sea show very different habits in their consumption of fats.

Nutritional consequences of the migra-
tion of North-African subjects to Seine Saint-Denis. P Miossec, B Betari, F Sedjari, J Paries, Jr Attali, P Valensi (Nutrition and Metabolic Diseases Laboratory, Jean Verdier Hospital, Paris Nord University, avenue du 14 juillet, 93140 Bondy, France).

Two hundred and seven healthy adult subjects, born in Maghreb and living in France for more than 1 year (group $M$ ) were compared to ninety-six healthy French agematched subjects born in France (group F) regarding food intakes and anthropometric and metabolic parameters. Mean age (39 \pm 0.7 vs $40.8 \pm 0.9$ year) and sex ratio were similar in the two groups. In $M$ the total caloric intake was higher than in F (2 $580 \pm$ 97 vs $1997 \pm 52 \mathrm{Kca} /$ day; $P<0.001)$ but the lipid (35.4 \pm 0.4 vs $40.0 \pm 0.5 \% ; P<0.001$ ), carbohydrate $(49.8 \pm 0.5$ vs $42.7 \pm 0.7 \% ; P$ $<0.001)$ and protein $(14.9 \pm 0.3$ vs $17.4 \pm$ $0.4 \% ; P<0.001)$ intakes were closer to the 